\title{
Casca de Café em Dietas de Vacas em Lactação: Consumo, Digestibilidade e Produção de Leite $^{1}$
}

\author{
Alexandre Lima de Souza ${ }^{2}$, Rasmo Garcia ${ }^{3}$, Sebastião de Campos Valadares Filho ${ }^{3}$, Fernanda \\ Cipriano Rocha ${ }^{4}$, José Maurício de Souza Campos ${ }^{3}$, Luciano da Silva Cabral ${ }^{5}$, Kátia Fernanda Gobbi ${ }^{6}$
}

RESUMO - Avaliaram-se o consumo, a digestibilidade, a produção e a composição do leite de vacas recebendo dietas contendo diferentes níveis de casca de café(0,0; 8,75; 17,5 e 26,25\% da MS) em substituição ao milho na ração concentrada. Foram utilizadas 12 vacas da raça Holandesa, em três quadrados latinos 4 x 4, distribuídas de acordo com o período de lactação. As dietas, isoprotéicas e com 14,0\% de proteína bruta (PB), foram constituídas de $60 \%$ de silagem de milho e $40 \%$ de ração concentrada, com base na MS. Os consumos de matéria seca(MS), PB e carboidratos totais (CT) não foram alterados, enquanto o de fibra em detergente neutro (FDN) aumentou com adição de casca de café. As digestibilidades da MS, PB, CT, FDN e carboidratos não-fibrosos (CNF) diminuíram com adição de casca de café na ração. A produção de leite e as quantidades de gordura, proteína, sólidos totais e suas concentrações no leite não foram alteradas com adição de casca de café nas dietas. Apesar de a casca de café ter reduzido a digestibilidade dos nutrientes da dieta essas alterações não foram capazes de reduzir a produção e a composição do leite, recomendando-se a inclusão deste resíduo em até 10,5\% na MS total da dieta em substituição ao milho da ração concentrada.

Palavras-chave: composição bromatológica, composição do leite, ração concentrada, resíduo agroindustrial

\section{Effects of Feeding Coffee Hulls on Intake, Digestibility and Milk Yield and Composition of Lactating Dairy Cows}

\begin{abstract}
It was studied the effects of replacing ground corn with coffee hulls on intake, apparent digestibility, and milk production and composition of lactating dairy cows. Twelve Holstein-Zebu dairy cows were blocked by days in milk and randomly assigned to three 4 x 4 Latin squares. The following levels of coffee hulls were included in the concentrate portion of the diet: 0.0 , 8.75, 17.5 , or $26.25 \%$ of dry mater (DM). Diets were formulated to be isonitrogenous (14\% CP) and contained a forage:concentrate ratio of 60:40 on DM basis. Inclusion of coffee hulls in the diet had no significant effects on intakes of DM, organic matter, CP, and total carbohydrates (TC). However, intake of neutral detergent fiber (NDF) increased linearly when coffee hulls replaced ground corn in the diet. Apparent total tract digestibilities of DM, CP, TC, NDF, and NFC all reduced linearly by increasing coffee hulls from 0.0 to $26.25 \%$ in the diet. Coffee hulls increased excretion of $\mathrm{N}$ in the feces resulting in a negative nitrogenous balance. The incremental levels of coffee hulls did not affect the urinary excretions of allantoin, uric acid, and purine derivatives as well as microbial protein synthesis. Milk yield and contents and yields of fat, protein, and total solids also were not affected by replacing ground corn with coffee hulls. It can be concluded that coffee hulls can be included up to $10.5 \%$ of the total dietary DM.
\end{abstract}

Key Words: agroindustrial residue, chemical-bromatologic composition, concentrate diet, milk composition

\section{Introdução}

A abertura do mercado interno a produtos lácteos internacionais, subsidiados na origem, e a carência de políticas estruturadas para o setor, associadas à constante elevação dos preços dos insumos agropecuários (alimentos concentrados e volumosos, fertilizantes e defensivos), representam alguns fatores que contribuem para a baixa sustentabilidade das granjas leiteiras (Santos, 2001). Os gastos com volumoso por litro de leite produzido são baixos e, geralmente, não represen- tam mais que $10 \%$ do custo total para se produzir um litro de leite (Pereira \& Correa 2001), enquanto o uso de alimentos concentrados contribui sensivelmente para elevar o preço do litro de leite produzido. Nesse sentido, a manipulação dos ingredientes utilizados na ração concentrada torna-se alternativa viável na redução dos gastos com alimentação e, conseqüentemente, diminui o custo do leite.

Os resíduos da agroindústria, em sua maioria, apresentam bom potencial para utilização na alimentação de ruminantes. Dependendo do valor nutritivo

\footnotetext{
${ }^{1}$ Projeto financiado pela Fundação de Amparo à Pesquisa do Estado de Minas Gerais (FAPEMIG)

2 Professor do curso de Zootecnia - UFMT. E.mail: alexandre@ufmt.br

3 Professor do Departamento de Zootecnia - UFV.

4 Zootecnista, DS, DZO/UFV.

5 Professor do curso de Zootecnia - FAMEV - UFMT.

${ }^{6}$ Zootecnista, MS.
} 
do material de origem, do processamento aplicado e do volume produzido, os resíduos podem substituir, em diferentes proporções, os alimentos tradicionalmente utilizados na formulação de concentrados.

Entre os diversos resíduos, a casca de café, resultante do beneficiamento do grão pelo método de via seca, em razão de sua disponibilidade em diferentes estados brasileiros (Anuário Estatístico do Brasil, 2000) e de sua composição química favorável, pode ser utilizada de diferentes formas na alimentação de bovinos.

Algumas pesquisas indicam a possibilidade técnico e econômica de se incluir casca de café como substituto ao milho desintegrado com palha e sabugo (MDPS) na ração concentrada de novilhos confinados (Barcelos et al., 1997) ou ainda na formulação de misturas múltiplas para animais suplementados a pasto (Nascimento, 2002). As informações sobre seu uso na alimentação de novilhas e vacas leiteiras ainda não permitem esclarecer a relação entre os níveis de inclusão na dieta e o consumo, a digestibilidade, o desempenho e a produção de leite.

Diante do volume de casca de café disponível e da necessidade de informações para a utilização mais racional deste resíduo na alimentação de bovinos leiteiros, conduziu-se este experimento objetivando avaliar o consumo, a digestibilidade aparente, a produção e a composição do leite de vacas consumindo dietas contendo diferentes níveis de inclusão de casca de café em substituição ao milho da ração concentrada.

\section{Material e Métodos}

O experimento foi realizado no setor de Pesquisa e Ensino em Gado de Leite do Departamento de Zootecnia da Universidade Federal de Viçosa no período de 1 으 de junho a 30 de julho de 2001. Foram utilizadas 12 vacas holandesas em lactação, puras e mestiças, com peso médio de 550 kg e produção de 24 kg de leite por dia, distribuídas em três quadrados latinos $4 \times 4$, de acordo com o período de lactação. O primeiro quadrado latino foi formado por vacas primíparas aos 41 dias de lactação e o segundo e terceiro, por vacas multíparas com média 37 e 25 dias de lactação, respectivamente. Cada período experimental teve duração de 15 dias - os sete primeiros dias para adaptação e os oito restantes para a coleta de amostras e medição do consumo e da produção de leite.
Os tratamentos foram constituídos de quatro níveis de casca de café $(0 ; 8,75 ; 17,5$ e 26,25\%, na MS) em substituição ao fubá de milho da ração concentrada, que corresponderam a 0; 3,5; 7,0 e 10,5\% de casca de café na MS total da dieta. As dietas, isoprotéicas e com $14,0 \%$ de PB, foram fornecidas ad libitum duas vezes ao dia, às 07 e 16h30, permitindo-se sobras de 5 a $10 \%$. Os animais receberam quatro dietas completas contendo, na matéria seca, $60 \%$ de silagem de milho e $40 \%$ de concentrado. Durante o fornecimento da alimentação, efetuou-se manualmente a mistura de concentrado e volumoso no comedouro. A composição percentual dos ingredientes das dietas encontra-se na Tabela 1.

A casca de café foi adquirida de indústria beneficiadora, na qual o processamento do grão é feito na forma seca. Na casca de café, estão contidos a polpa, a mucilagem e o pergaminho ou casquinha (Caielli, 1984). Antes de ser adicionada e misturada aos ingredientes da ração concentrada, a casca de café foi processada no mesmo moinho e com a mesma peneira utilizada na moagem do milho. A composição química do volumoso, da casca de café e das rações concentradas encontra-se na Tabela 2.

As vacas foram alojadas em galpão coberto, com baias individuais (sistema tie stalls), piso de borracha e dotadas de comedouro e bebedouro. As vacas foram ordenhadas diariamente às $6 \mathrm{~h} 30$ e $16 \mathrm{~h}$ e suas produções foram registradas individualmente. A pesagem dos animais foi realizada logo após a ordenha da manhã e no início e final de cada período experimental.

Tabela 1 - Composição percentual dos ingredientes da dieta (\% na MS)

Table 1 - ingredient composition of diets (\% DM)

\begin{tabular}{lcccc}
\hline $\begin{array}{l}\text { Ingrediente } \\
\text { Ingredient }\end{array}$ & \multicolumn{4}{c}{ Dieta $^{1}$} \\
& Diet $^{1}$ \\
\cline { 2 - 5 } & 0 & 8,75 & 17,5 & 26,25 \\
\hline $\begin{array}{l}\text { Silagem de milho } \\
\text { Corn silage }\end{array}$ & 60,0 & 60,0 & 60,0 & 60,0 \\
$\begin{array}{l}\text { Farelo de soja } \\
\text { Soybean meal }\end{array}$ & 18,0 & 18,0 & 18,0 & 18,0 \\
$\begin{array}{l}\text { Fubá de milho } \\
\text { Ground corn }\end{array}$ & 20,1 & 16,6 & 13,1 & 9,6 \\
$\begin{array}{l}\text { Casca de café } \\
\begin{array}{l}\text { Coffee hulls } \\
\text { UréiaUrea }\end{array}\end{array}$ & 0 & 3,5 & 7,0 & 10,5 \\
$\begin{array}{l}\text { Mistural mineral } \\
\text { Mineral mix }\end{array}$ & 0,36 & 0,36 & 0,36 & 0,36 \\
\hline
\end{tabular}

${ }^{1}$ Porcentagem de casca de café no concentrado (base da MS).

${ }_{1}^{1}$ Percent of coffee hulls in the concentrate (DM basis). 
Durante todo o período experimental, as sobras de cada animal foram pesadas diariamente antes do fornecimento das dietas, coletando-se uma alíquota, que foi acondicionada em sacos plásticos e guardada em freezer. Amostras da silagem de milho, das sobras e da ração concentrada foram coletadas diariamente, durante os oitos dias finais de cada período experimental, e misturada, retirando-se uma amostra composta por animal. As amostras de leite, coletadas na $2^{\underline{a}}$ e $1^{\underline{a}}$ ordenhas do $12^{\underline{o}}$ e $13^{\underline{o}}$ dias, respectivamente, de cada período experimental foram misturadas proporcionalmente à produção de leite e analisadas quanto aos teores de proteína bruta, gordura e sólidos totais. Os teores de PB foram estimados conforme procedimentos descritos por Silva \& Queiroz (2002), os de sólidos totais, pela secagem de amostras de leite em estufa a $105^{\circ} \mathrm{C}$, e os de gordura foram determinados em aparelho modelo MK 2.5. A produção de leite corrigida para 4,0\% de gordura (PLC) foi obtida pela equação citada pelo National Research Council (2001), em que PLC $=0,4 \times \mathrm{PL}+15 \times$ (kg de gordura).

A coleta de fezes foi realizada às 6,11 e 15 h do $10^{\circ}$, 12 e e 14 o dias, respectivamente, de cada período experimental. As amostras foram obtidas diretamente da ampola retal e, posteriormente, acondicionadas em sacos plásticos e armazenadas em freezer. A estimativa da excreção fecal foi efetuada utilizando-se a fibra em detergente ácido indigestível (FDAI) como indicador, conforme Cochran et al. (1986), com algumas alterações. Neste procedimento, as amostras de alimentos, sobras e fezes foram colocadas em sacos Ankon (Filter bags F57) incubadas no rúmen por um período de 144 horas. O material remanescente da incubação foi previamente lavado com água e submetido à extração com detergente ácido, cujo resíduo foi considerado FDAI.

As amostras de silagem de milho, sobras e fezes foram pré-secas em estufas de ventilação forçada a $60^{\circ} \mathrm{C}$, durante 72 horas. Em seguida, juntamente com as amostras de concentrado, foram processadas em moinho tipo Willey com peneira de $1 \mathrm{~mm}$ e armazenadas para posteriores análises. As análises dos teores de matéria seca (MS), matéria orgânica (MO), nitrogênio total, fibra em detergente neutro (FDN), extrato etéreo (EE), nitrogênio insolúvel em detergente neutro (NIDN) e nitrogênio insolúvel em detergente ácido (NIDA) foram realizadas segundo técnicas descritas por Silva \& Queiroz (2002). Os teores de carboidratos totais (CT) foram calculados conforme as equações propostas por Sniffen et al. (1992), em que CT $=100$ - (\%PB + \%EE + \%Cinzas) e os teores de carboidratos não-fibrosos (CNF), pela fórmula CNF $=\mathrm{CT}-\mathrm{FDN}$.

As concentrações de nutrientes digestíveis totais estimados $\left(\mathrm{NDT}_{\mathrm{EST}}\right)$ dos alimentos, das rações concentradas e das dietas foram calculadas conforme equações propostas pelo NRC (2001). Utilizou-se, para o cálculo do NDT $_{\text {EST }}$ do volumoso e da casca de café, a equação:

$$
\mathrm{NDT}_{\mathrm{EST}}=0,98\left[100-\left(\mathrm{FDN}_{\mathrm{p}}+\mathrm{PB}+\mathrm{EE}+\text { cinza }\right)\right] \mathrm{x}
$$
$\mathrm{PF}+\mathrm{PB} \times \exp [-1,2 \times(\mathrm{PIDA} / \mathrm{PB})]+2,25 \times(\mathrm{EE}-1)+$ $0,75 \times\left(\mathrm{FDN}_{\mathrm{p}}\right.$ - Lignina $\left.) \mathrm{x}\left[1 \text { - (Lignina/FDN }{ }_{\mathrm{p}}\right)^{0,667}\right]-7$

e, para o cálculo do NDT $_{\text {EST }}$ das rações concentradas, adotou-se a equação:

$$
\begin{gathered}
\mathrm{NDT}_{\mathrm{EST}}=0,98\left[100-\left(\mathrm{FDN}_{\mathrm{p}}+\mathrm{PB}+\mathrm{EE}+\text { cinza }\right)\right] \\
\mathrm{x} \mathrm{PF}+\mathrm{PB} \times \exp [-0,4 \mathrm{x}(\mathrm{PIDA} / \mathrm{PB})]+2,25 \mathrm{x}(\mathrm{EE} \\
-1)+0,75 \times\left(\mathrm{FDN}_{\mathrm{p}}-\text { lignina }\right) \mathrm{x}[1-(\text { lignina/ } \\
\text { FDN } \left.\left._{\mathrm{p}}\right)^{0,667}\right]-7
\end{gathered}
$$

em que: $\mathrm{FDN}_{\mathrm{p}}=$ FDN - PIDN (PIDN = nitrogênio insolúvel em detergente neutro x 6,25); PF = efeito do processamento físico na digestibilidade dos carboidratos não-fibrosos; PIDA = nitrogênio insolúvel em detergente ácido x 6,25. Para valores de $\mathrm{EE}<1$, na equação $(\mathrm{EE}-1)=0$

Para a silagem de milho, utilizou-se valor de 0,94 para PF, enquanto, para a casca de café e os concentrados, adotou-se valor de PF igual a 1 . Os valores de nutrientes digestíveis totais (NDT) calculados para as diferentes dietas foram obtidos pela equação:

$$
\mathrm{NDT}=\mathrm{PBD}+\mathrm{EED} \times 2,25+\mathrm{FDND}+\mathrm{CNFD}
$$

em que: $\mathrm{PBD}=$ proteína bruta digestível; $\mathrm{EED}=$ extrato etéreo digestível; FDND = fibra em detergente neutro digestível; CNFD = carboidratos não-fibrosos digestíveis.

Os resultados foram submetidos às análises de variância e de regressão, a 5\% de significância, pelo Programa SAEG, versão 7.1 (UFV, 1997). A escolha do melhor modelo foi feita com base no coeficiente de determinação e na significância dos coeficientes de regressão, utilizando-se o teste “ $t$ ” de Student a 5\% de probabilidade. 


\section{Resultados e Discussão}

Considerando-se a composição dos alimentos (Tabela 2), destacam-se os altos teores de nitrogênio insolúvel em detergente neutro (NIDN), nitrogênio insolúvel em detergente ácido (NIDA), lignina (14,7\%) e FDAI $(38,1 \%)$ da casca de café em comparação aos da ração concentrada sem casca de café e a silagem de milho. Uma vez que estes compostos são de lenta digestão ou indigestíveis pelas enzimas produzidas pelos microrganismos do rúmen (Jung \& Allen, 1995; Licitra et al., 1996), suas concentrações na casca de café podem contribuir como fator limitante para a inclusão desse resíduo na dieta de vacas leiteiras.

Os coeficientes de digestibilidade aparente da MS, MO, CT, FDN, CNF, PB e EE e a concentração de nutrientes digestíveis totais (NDT ${ }_{\text {OBS }}$ ) são apresentados na Tabela 3. Apesar de o consumo de MS não ter sido alterado, houve efeito linear $(\mathrm{P}<0,05)$ dos níveis de casca de café sobre os coeficientes de digestibilidade da MS, MO e PB, estimando-se redução de 0,376; 0,368 e 0,300 unidades percentuais para cada unidade de casca adicionada, respectivamente.
A redução no consumo de componentes nãofibrosos CNF, os quais apresentam disponibilidade rápida e praticamente completa no trato gastrintestinal dos ruminantes, e as diferenças quantitativas entre os constituintes da parede celular do milho (Valadares Filho et al., 2001) e da casca de café (Tabela 2) podem ser consideradas os principais responsáveis pela redução na digestibilidade da MS das dietas com casca de café. A redução na digestibilidade da PB resultou dos maiores teores de nitrogênio na forma de nitrogênio insolúvel em detergente neutro (NIDN) e em detergente ácido (NIDA) na casca de café (Tabela 2) em relação aos valores de 9,29\% de NIDN e de 5,25\% de NIDA presentes no milho (Valadares Filho et al., 2001). O nitrogênio insolúvel em detergente neutro, mas solúvel em detergente ácido, é digestível, mas de lenta degradação no rúmen. O nitrogênio na forma de NIDA parece ser resistente e praticamente indigestível e geralmente é associado à lignina e a outros compostos de difícil degradação (Licitra et al., 1996).

Detectou-se efeito linear $(\mathrm{P}<0,05)$ dos níveis de casca sobre as digestibilidades dos CT, FDN e CNF, estimando-se redução de 0,395; 0,399 e 0,173 unidades

Tabela 2 - Composição química da silagem de milho, da casca de café e das rações concentradas Table 2 - Chemical composition of corn silage, coffee hulls and concentrate

\begin{tabular}{|c|c|c|c|c|c|c|}
\hline \multirow[t]{2}{*}{ Item } & \multirow[t]{2}{*}{$\begin{array}{l}\text { Silagem de milho } \\
\text { Corn silage }\end{array}$} & \multirow[t]{2}{*}{$\begin{array}{c}\text { Casca de café } \\
\text { Coffee hulls }\end{array}$} & \multicolumn{4}{|c|}{$\begin{array}{c}\text { Concentrado }^{1} \\
\text { Concentrate }\end{array}$} \\
\hline & & & 0 & 8,75 & 17,5 & 26,25 \\
\hline $\mathrm{MO}^{2}(\mathrm{OM})$ & 94,2 & 92,6 & 92,2 & 91,5 & 90,9 & 90,3 \\
\hline $\mathrm{PB}^{2}(C P)$ & 6,0 & 8,4 & 26,1 & 26,1 & 26,0 & 26,0 \\
\hline $\mathrm{NIDN}^{3}(N D I N)$ & 17,3 & 38,4 & 3,4 & 4,2 & 4,9 & 7,0 \\
\hline $\mathrm{EE}^{2}$ & 2,8 & 1,0 & 3,3 & 3,0 & 2,7 & 2,4 \\
\hline $\mathrm{CT}^{2}(\mathrm{TC})$ & 85,4 & 83,2 & 62,8 & 62,4 & 62,2 & 61,9 \\
\hline $\mathrm{FDN}^{2}(N D F)$ & 52,9 & 59,1 & 11,7 & 16,2 & 20,0 & 25,0 \\
\hline $\mathrm{FDN}_{n}^{2}\left(N D F_{n}\right)$ & 51,8 & 55,9 & 10,8 & 15,1 & 18,7 & 23,2 \\
\hline $\mathrm{FDN}_{\mathrm{Cp}}^{\mathrm{P}}\left(N D F_{p}\right)$ & 50,9 & 53,6 & 10,5 & 14,6 & 18,0 & 22,2 \\
\hline CNF (NFC) & 34,5 & 29,6 & 52,3 & 47,8 & 44,2 & 39,7 \\
\hline $\mathrm{P}^{2}$ & 0,04 & 0,11 & 0,63 & 0,65 & 0,69 & 0,67 \\
\hline $\mathrm{K}^{2}$ & 2,15 & 2,37 & 1,11 & 1,18 & 1,29 & 1,49 \\
\hline $\mathrm{NDT}_{\mathrm{FST}^{2,4}(T D N)}$ & 64,15 & 44,07 & 80,95 & 75,85 & 71,73 & 66,79 \\
\hline $\mathrm{EL}_{\mathrm{L}}{ }^{4} \mathrm{EST}$ cal/kg MS $\left(N_{L} \mathrm{Mcal} \mathrm{kg} D M\right)$ & 1,44 & 0,85 & 2,13 & 1,98 & 1,86 & 1,71 \\
\hline
\end{tabular}

${ }^{1}$ Porcentagem de casca de café no concentrado (base da MS) (Percentage of coffee hulls on concentrate, DM basis); ${ }^{2}$ Valores em porcentagem da MS (Values in DM basis); ${ }^{3}$ Valores em porcentagem do nitrogênio total (Values in the percentage of total nitrogen); ${ }^{4}$ Estimado pelo NRC (2001) (Estimated by the NRC, 2001). 
Tabela 3 - Coeficientes médios de digestibilidade e valores de nutrientes digestíveis totais observados (NDT) e de energia líquida de lactação $\left(E L_{L}\right)$ em função dos níveis de casca de café na ração concentrada (\% na MS), coeficiente de variação $(\mathrm{CV})$ e equações de regressão

Table 3 - Mean values of digestibility coefficients and total digestible nutrients observed (TDN $\left.N_{O B S}\right)$ and net energy of lactation in response to the increasing levels of coffee hulls (\% DM), coefficients of variation and regression equations

\begin{tabular}{|c|c|c|c|c|c|c|}
\hline \multirow[t]{2}{*}{ Item } & \multicolumn{4}{|c|}{$\begin{array}{l}\text { Dieta } \\
\text { Diet }\end{array}$} & \multirow[t]{2}{*}{$\mathrm{CV}$} & \multirow[t]{2}{*}{$\begin{array}{l}\text { Equação de regressão } \\
\text { Regression equation }\end{array}$} \\
\hline & 0 & 8,75 & 17,5 & 26,25 & & \\
\hline CDMS (DCDM) & 71,6 & 68,3 & 65,7 & 61,5 & 2,3 & $\hat{Y}=71,74-0,3763 X\left(r^{2}=0,99\right)$ \\
\hline CDMO (DCOM) & 73,1 & 69,8 & 67,2 & 63,3 & 2,3 & $\hat{\mathrm{Y}}=73,18-0,3684 \mathrm{X}\left(\mathrm{r}^{2}=0,99\right)$ \\
\hline $\mathrm{CDPB}(D C C P)$ & 71,3 & 69,4 & 67,8 & 63,0 & 3,1 & $\hat{\mathrm{Y}}=71,80-0,3005 \mathrm{X}\left(\mathrm{r}^{2}=0,93\right)$ \\
\hline CDFDN (DCNDF) & 56,9 & 52,5 & 49,8 & 46,1 & 4,9 & $\hat{Y}=56,55-0,3999 X\left(r^{2}=0,99\right)$ \\
\hline CDCT (DCTC) & 73,6 & 70,1 & 67,3 & 63,0 & 3,2 & $\hat{\mathrm{Y}}=73,72-0,3954 \mathrm{X}\left(\mathrm{r}^{2}=0,99\right)$ \\
\hline CDCNF (DCNFC) & 86,7 & 84,8 & 83,6 & 82,1 & 4,6 & $\hat{\mathrm{Y}}=86,59-0,1737 \mathrm{X}\left(\mathrm{r}^{2}=0,99\right)$ \\
\hline $\operatorname{CDEE}(D C E E)$ & 76,1 & 74,0 & 75,1 & 71,7 & 6,7 & $\hat{\mathrm{Y}}=76,08-0,1402 \mathrm{X}\left(\mathrm{r}^{2}=0,69\right)$ \\
\hline $\mathrm{NDT}^{1}(T D N)$ & 71,0 & 67,3 & 64,7 & 60,5 & 2,6 & $\hat{\mathrm{Y}}=70,99-0,3894 \mathrm{X}\left(\mathrm{r}^{2}=0,99\right)$ \\
\hline $\mathrm{EL}_{\mathrm{L}}^{2}$ & 1,72 & 1,66 & 1,61 & 1,55 & - & - \\
\hline
\end{tabular}

${ }^{1}$ Valores em porcentagem da MS (Values in percentage of dry matter); ${ }^{2} \mathrm{Mcal} / \mathrm{kg} \mathrm{MS}$ (Mcal/kg DM).

percentuais para cada unidade de casca adicionada, respectivamente. O decréscimo na digestibilidade dos CT pode ser reflexo da menor digestibilidade dos CNF e da fração fibrosa. Por sua vez, a digestibilidade da fração FDN pode ter sido influenciada pelos altos teores de lignina na casca de café (Tabela 2). A lignina é um dos principais fatores limitantes da digestão dos polissacarídios da parede celular (Jung \& Allen, 1995). A influência negativa da lignina sobre a fração fibrosa da casca de café pode ser confirmada pelo alto teor de fibra em detergente ácido indigestível neste resíduo (Tabela 2). Os baixos valores de digestibilidade in vitro da fração fibrosa da casca de café foram confirmados por Souza et al. (2001), que registraram valor médio de 28,9\% para a digestibilidade da FDN.

Verificou-se efeito linear $(\mathrm{P}<0,05)$ dos níveis de casca de café sobre a digestibilidade do EE, estimando-se redução de 0,140 unidades percentuais para cada unidade de casca adicionada. O baixo consumo de EE, somado a sua excreção endógena nas fezes, pode ter contribuído para a diminuição aparente da digestibilidade deste nutriente, observando-se efeitos mais pronunciados à medida que se elevou a quantidade de casca nas dietas. A redução na digestibilidade aparente dos nutrientes e a maior ingestão de componentes fibrosos com a inclusão de casca de café na dieta resultaram em menores teores de $\mathrm{NDT}_{\mathrm{OBS}}$ $(\mathrm{P}<0,05)$ nas dietas, estimando-se redução de 0,389 unidades percentuais para cada unidade de casca adicionada.
Os consumos médios diários de matéria seca (MS), matéria orgânica (MO), proteína bruta (PB), extrato etéreo (EE), carboidratos totais (CT), fibra em detergente neutro (FDN), carboidratos não-fibrosos (CNF) e nutrientes digestíveis totais (NDT) e suas respectivas equações de regressão encontram-se na Tabela 4. Os consumos de MS e MO, expressos em kg/ dia e em porcentagem do PV (\%PV), não diferiram $(\mathrm{P}>0,05)$ entre as dietas, registrando-se valores médios de 18,$5 ; 17,2 \mathrm{~kg} /$ dia e de 3,33 e $3,10 \%$ PV, respectivamente. Em algumas pesquisas, tem-se relatado que a polpa e a casca de café, quando incluídas na dieta de ruminante, podem afetar negativamente o consumo e que estas alterações estariam associadas à presença de compostos fenólicos nestes resíduos (Vargas et al., 1982; Ramirez-Martine, 1988). É possível que alguns destes compostos, como a cafeína, aumentem a mobilização de ácidos graxos livres para o plasma sanguíneo, resultando em redução do apetite e do consumo de alimentos (Braham et al., 1973; Hawkins \& Davis,1970). Todavia, em estudos realizados com bovinos no Brasil, não foram registradas reduções no consumo de matéria seca (Barcelos et al., 1997).

As alterações no consumo MS podem ser atribuídas, entre outros fatores, à quantidade de casca de café adicionada à dieta. Porém, ainda não foram definidos níveis máximos de inclusão na dieta de ruminantes, sem que haja prejuízos no consumo de MS e desempenho dos animais. Os consumos médios diários de MS de casca de café foram de 0,0; 644,7; 1272,6 e 
1963,5 g para os animais que receberam rações concentradas contendo 0,$0 ; 8,75 ; 17,5$; e $26,25 \%$ deste resíduo, respectivamente, que, por sua vez, corresponderam aos níveis de 0,0; 3,5; 7,0; e 10,5\% de casca de café na MS da dieta. Não foi observada diferença para a ingestão de PB com adição de casca de café na ração concentrada, observando-se consumo médio 2,72 kg/dia, que pode ser atribuído à ausência de efeito dos níveis de casca sobre o consumo de MS e também ao fato de as dietas terem sido isoprotéicas.

Embora os consumos de MS e CT não tenham sido alterados, a análise de regressão revelou efeito linear $(\mathrm{P}<0,05)$ dos níveis de casca de café sobre os consumos de FDN e CNF expressos em kg/dia e \% PV, estimando-se acréscimo de 44,2 g e redução de 52,3 g/unidade de casca adicionada, respectivamente. Esse resultado decorreu da maior concentração de componentes fibrosos e da menor concentração de CNF da casca de café (Tabela, 2) em relação ao milho fubá (Valadares Filho et al., 2001). As concentrações médias de CNF foram de 42,2; 39,9; 37,7 e 35,2\% para as dietas com $0 ; 8,75 ; 17,5$ e 26,25\% de casca de café, respectivamente, próximas à de $37 \%$ encontrada por
Valadares et al. (1999), que relataram maior consumo de MS e produção de leite em vacas recebendo como volumoso silagem de alfafa.

Houve efeito linear $(\mathrm{P}<0,05)$ dos níveis de casca de café sobre os consumos de $\mathrm{EE}$ e $\mathrm{NDT}_{\mathrm{OBS}}$, que apresentaram reduções de 2,8 e 77,5 g/unidade de casca adicionada, respectivamente. Uma vez que o consumo de MS não foi alterado, a redução no consumo de EE foi atribuída aos baixos teores deste nutriente na casca de café (Tabela 2) e, conseqüentemente, à sua menor concentração nas dietas. A diminuição no consumo de NDT, no entanto, pode ser atribuída à redução simultânea nos consumos de EE e CNF, nutrientes de alta digestibilidade e ótimo valor energético, ao mesmo tempo em que ocorreu aumento no consumo de carboidratos fibrosos, que, por sua vez, influenciam negativamente a disponibilidade dos nutrientes em razão de sua lenta e incompleta digestão no aparelho digestivo (Jung \& Allen, 1995; Licitra et al., 1996).

Os valores médios observados para a produção e composição do leite e a variação no peso animal vivo são apresentados na Tabela 5. Apesar de o consumo de fibra ter aumentado e o consumo de NDT e a

Tabela 4 - Consumos médios diários de matéria seca (MS) e dos nutrientes da dieta, em função dos níveis de casca de café na ração concentrada (base da MS), coeficiente de variação (CV) e equações de regressão

Table 4 - Mean intake of dry matter (DM) and nutrients in response to the increasing levels of coffee hulls (\% DM), coefficients of variation and regression equations

\begin{tabular}{|c|c|c|c|c|c|c|}
\hline \multirow[t]{2}{*}{ Item } & \multicolumn{4}{|c|}{$\begin{array}{l}\text { Dieta } \\
\text { Diet }\end{array}$} & \multirow[t]{2}{*}{$\mathrm{CV}$} & \multirow[t]{2}{*}{$\begin{array}{c}\text { Equação de regressão } \\
\text { Regression equation }\end{array}$} \\
\hline & 0 & 8,75 & 17,5 & 26,25 & & \\
\hline \multicolumn{7}{|c|}{$\begin{array}{l}\text { Consumo (kg/dia) } \\
\text { Intake (kg/day) }\end{array}$} \\
\hline MS (DM) & 18,82 & 18,42 & 18,18 & 18,70 & 3,2 & $\hat{Y}=18,53$ \\
\hline $\mathrm{MO}(\mathrm{OM})$ & 17,58 & 17,15 & 16,87 & 17,32 & 3,2 & $\hat{Y}=17,23$ \\
\hline $\mathrm{PB}(C P)$ & 2,78 & 2,70 & 2,67 & 2,74 & 3,8 & $\hat{Y}=2,72$ \\
\hline $\mathrm{CT}(T C)$ & 14,28 & 13,97 & 13,75 & 14,13 & 3,2 & $\hat{\mathrm{Y}}=14,03$ \\
\hline $\mathrm{FDN}(N D F)$ & 6,33 & 6,59 & 6,88 & 7,52 & 3,8 & $\hat{\mathrm{Y}}=6,25-0,0442 \mathrm{X}\left(\mathrm{r}^{2}=0,95\right)$ \\
\hline $\mathrm{CNF}(N F C)$ & 7,94 & 7,35 & 6,85 & 6,58 & 4,0 & $\hat{\mathrm{Y}}=7,87-0,0524 \mathrm{X}\left(\mathrm{r}^{2}=0,97\right)$ \\
\hline $\operatorname{NDT}^{1}(T D N)$ & 13,37 & 12,39 & 11,76 & 11,32 & 3,9 & $\hat{\mathrm{Y}}=13,23-0,0776 \mathrm{X}\left(\mathrm{r}^{2}=0,97\right)$ \\
\hline $\mathrm{EL}_{\mathrm{L}}{ }^{1}, \operatorname{Mcal}\left(N E_{l}\right)$ & 31,79 & 30,68 & 29,80 & 28,68 & - & - \\
\hline \multicolumn{7}{|c|}{$\begin{array}{c}\text { Consumo (\% PV) } \\
\text { Intake }(\% \text { BW) }\end{array}$} \\
\hline MS (DM) & 3,39 & 3,30 & 3,27 & 3,36 & 3,9 & $\hat{Y}=3,33$ \\
\hline $\mathrm{MO}(\mathrm{OM})$ & 3,17 & 3,07 & 3,03 & 3,11 & 3,9 & $\hat{Y}=3,09$ \\
\hline $\mathrm{CT}(T C)$ & 2,57 & 2,50 & 2,47 & 2,54 & 3,8 & $\hat{\mathrm{Y}}=2,52$ \\
\hline $\mathrm{FDN}(N D F)$ & 1,14 & 1,18 & 1,23 & 1,36 & 4,3 & $\hat{\mathrm{Y}}=1,12-0,0080 \mathrm{X}\left(\mathrm{r}^{2}=0,92\right)$ \\
\hline $\mathrm{CNF}(N F C)$ & 1,43 & 1,32 & 1,24 & 1,18 & 4,5 & $\hat{\mathrm{Y}}=1,42-0,0097 \mathrm{X}\left(\mathrm{r}^{2}=0,98\right)$ \\
\hline
\end{tabular}

1 Valores obtidos conforme o NRC (2001) (Estimated by the NRC, 2001). 
digestibilidade dos nutrientes das dietas terem reduzido com a inclusão de casca de café, a produção de leite (PL), a produção de leite corrigida para 4\% de gordura e a eficiência de produção de leite, expressa em $\mathrm{kg}$ de leite produzido/kg de MS consumida não foram alterados $(\mathrm{P}<0,05)$, possivelmente em decorrência do elevado consumo de MS (Tabela 4), que permitiu aos animais que receberam dietas com casca de café ingerirem quantidades de proteína próximas às exigências de 2,74 kg de $\mathrm{PB}$ e superiores às de 28,45 Mcal de energia líquida, propostas pelo NRC (2001) para vacas lactantes com peso corporal médio de 550 kg e produções médias diárias de 23,4kg com $4,0 \%$ de gordura.

As concentrações e quantidades de $\mathrm{PB}$, gordura e sólidos totais do leite não foram alteradas $(\mathrm{P}>0,05)$ pelos níveis de casca de café, registrando-se teores médios de 3,1; 4,0 e 12,2\%, respectivamente. Resultados semelhantes para composição do leite foram encontrados por Barcelos et al. (1996), que avaliaram a inclusão de casca de café na dieta de vacas com média de produção de leite de $16,9 \mathrm{~kg} /$ dia.
Considerando-se que as vacas foram pesadas apenas uma vez no final de cada período experimental e que não foram submetidas a jejum antes das pesagens, a variação no peso animal vivo não deve ser vista como um efeito direto do resíduo avaliado, pois parte das diferenças pode ter resultado de variações ocasionais no consumo de MS no dia anterior às pesagens. Também deve ser ressaltado que o coeficiente de variação determinado para esta variável refletiu seu alto grau de instabilidade.

Na Tabela 6 encontram-se os dados referentes ao custo das dietas, à receita proveniente da venda do leite e à margem bruta, para as quais foram computados apenas os dois primeiros itens. A redução no custo das dietas contendo casca de café foi atribuída ao efeito principal da substituição do milho pela casca e pequena parte desta diferença foi causada pelas variações no consumo médio de MS das dietas (Tabela 4).

As dietas com $26 \%$ de casca de café foram as que apresentaram menor custo com alimentação, menor custo por unidade de leite produzido e a maior receita, contribuindo para uma margem bruta adicional de

Tabela 5 - Produções médias diárias de leite $(P L)$ e de leite corrigida para 4\% de gordura (PLG), nutrientes, eficiência de produção de leite, variação no peso animal vivo (VPV), de acordo com os níveis de casca de café na ração concentrada (base da MS), coeficiente de variação (CV) e equações de regressão

Table 5 - Mean values of daily milk yield (DMY) and 4.0\% fat corrected milk (FCM), contents and yields of milk components, body weight change (BWC), in response to the increasing levels of coffee hulls (\% DM), coefficient of variation and regression equations

\begin{tabular}{|c|c|c|c|c|c|c|}
\hline \multirow[t]{2}{*}{ Item } & \multicolumn{4}{|c|}{$\begin{array}{l}\text { Dieta } \\
\text { Diet }\end{array}$} & \multirow[t]{2}{*}{$\mathrm{CV}$} & \multirow[t]{2}{*}{$\begin{array}{c}\text { Equações de regressão } \\
\text { Regression equations }\end{array}$} \\
\hline & 0 & 8,75 & 17,5 & 26,25 & & \\
\hline $\begin{array}{l}\text { PL (kg/vaca) } \\
\text { MP (kg/cow) }\end{array}$ & 23,03 & 23,72 & 22,91 & 24,08 & 6,9 & $\hat{\mathrm{Y}}=23,43$ \\
\hline $\begin{array}{l}\text { PLG (kg/vaca) } \\
M P(k g / \text { cow })\end{array}$ & 22,27 & 23,68 & 22,98 & 23,93 & 8,3 & $\hat{Y}=23,21$ \\
\hline $\begin{array}{l}\text { Eficiência } \\
\text { Efficiency }\end{array}$ & 0,85 & 0,80 & 0,81 & 0,80 & 5,3 & $\hat{\mathrm{Y}}=0,81$ \\
\hline $\begin{array}{l}\text { Gordura }(\%) \\
\text { Fat }(\%)\end{array}$ & 3,86 & 4,06 & 4,06 & 4,02 & 10,6 & $\hat{Y}=4,00$ \\
\hline $\begin{array}{l}\text { Gordura }(g) \\
\text { Fat }(g)\end{array}$ & 870,9 & 946,1 & 921,0 & 952,9 & 11,1 & $\hat{\mathrm{Y}}=922,7$ \\
\hline $\begin{array}{l}\text { Proteína bruta (\%) } \\
\text { Crude protein (\%) }\end{array}$ & 3,07 & 3,12 & 3,12 & 3,10 & 6,4 & $\hat{\mathrm{Y}}=3,10$ \\
\hline $\begin{array}{l}\text { Proteína bruta (g) } \\
\text { Crude protein }(\mathrm{g})\end{array}$ & 694,9 & 736,7 & 714,8 & 735,7 & 8,6 & $\hat{\mathrm{Y}}=720,5$ \\
\hline $\begin{array}{l}\text { Sólidos totais (\%) } \\
\text { Total solids (\%) }\end{array}$ & 12,35 & 12,23 & 12,17 & 12,14 & 4,5 & $\hat{\mathrm{Y}}=12,22$ \\
\hline $\begin{array}{l}\text { Sólidos totais (kg) } \\
\text { Total solids (\%) }\end{array}$ & 2,82 & 2,89 & 2,77 & 2,90 & 7,4 & $\hat{Y}=2,84$ \\
\hline $\begin{array}{l}\operatorname{VPV}(g) \\
B W C(g)\end{array}$ & $+377,7$ & $+483,3$ & $+72,2$ & $+488,8$ & 147,1 & $\hat{\mathrm{Y}}=355,5$ \\
\hline
\end{tabular}

$1_{\mathrm{kg}}$ de leite/kg de MS consumida ( $\mathrm{kg}$ of milk/kg of DM intake). 
Tabela 6 - Gastos com alimentação e receitas obtidas com a venda do leite, de acordo com os níveis de casca de café na ração concentrada (base da MS)

Table 6 - Feeding ingredient costs and milk incoming values in response to the increasing levels of coffee hulls (\% DM)

\begin{tabular}{|c|c|c|c|c|}
\hline \multirow[t]{2}{*}{ Item } & \multicolumn{4}{|c|}{$\begin{array}{c}\text { Dieta } \\
\text { Diet }\end{array}$} \\
\hline & 0,0 & 8,75 & 17,5 & 26,25 \\
\hline \multicolumn{5}{|l|}{ Despesas } \\
\hline \multicolumn{5}{|l|}{ Expenses } \\
\hline \multicolumn{5}{|l|}{ Volumoso $^{1}$} \\
\hline \multicolumn{5}{|l|}{ Forage $^{1}$} \\
\hline Silagem de milho (kg/vaca/dia) & 32,3 & 31,6 & 31,2 & 32,1 \\
\hline Corn silage (kg/cow/day) & & & & \\
\hline Custo da silagem (R\$/vaca/dia) & 1,45 & 1,42 & 1,40 & 1,44 \\
\hline \multicolumn{5}{|l|}{ Silage cost $(R \$ /$ cow/day $)$} \\
\hline \multicolumn{5}{|l|}{ Concentrado $^{1}$} \\
\hline \multicolumn{5}{|l|}{ Concentrate $^{1}$} \\
\hline Farelo de soja (kg/vaca/dia) & 3,85 & 3,77 & 3,72 & 3,83 \\
\hline \multicolumn{5}{|l|}{ Soybean meal (kg/cow/day) } \\
\hline Custo (R\$/vaca/dia) & 2,46 & 2,41 & 2,38 & 2,45 \\
\hline \multicolumn{5}{|l|}{$\operatorname{Cost}(R \$ /$ cow/day $)$} \\
\hline Fubá de milho (kg/vaca/dia) & 4,30 & 3,47 & 2,71 & 2,04 \\
\hline \multicolumn{5}{|l|}{ Ground corn (kg/cow/day) } \\
\hline Custo (R\$/vaca/dia) & 1,72 & 1,39 & 1,08 & 0,82 \\
\hline \multicolumn{5}{|l|}{ Cost (kg/cow/day) } \\
\hline Casca de café (kg/vaca/dia) & 0,0 & 0,75 & 1,48 & 2,28 \\
\hline \multicolumn{5}{|l|}{ Coffee hulls (kg/cow/day) } \\
\hline Custo (R\$/vaca/dia) & 0,0 & 0,0 & 0,0 & 0,0 \\
\hline \multicolumn{5}{|l|}{$\operatorname{Cost}(R \$ /$ cow/day $)$} \\
\hline Mineral suplemento (g/vaca/dia) & 359,8 & 352,2 & 347,6 & 357,5 \\
\hline \multicolumn{5}{|l|}{ Mineral supplement (g/cow/day) } \\
\hline Custo do suplemento (R\$/vaca/dia) & 0,32 & 0,32 & 0,32 & 0,32 \\
\hline \multicolumn{5}{|l|}{$\operatorname{Cost}(R \$ /$ cow/day $)$} \\
\hline Custo do concentrado ( $\mathrm{R} \$ / \mathrm{vaca} / \mathrm{dia})$ & 4,5 & 4,12 & 3,78 & 3,59 \\
\hline \multicolumn{5}{|l|}{$\operatorname{Cost}(R \$ /$ cow/day $)$} \\
\hline \multirow{2}{*}{\multicolumn{5}{|c|}{$\begin{array}{l}\text { Custo da dieta (R\$/vaca/dia) } \\
\text { Cost }(R \$ / \text { cow/day) }\end{array}$}} \\
\hline & & & & \\
\hline Custo do leite (R $\$$ /kg) & 0,30 & 0,27 & 0,26 & 0,25 \\
\hline \multicolumn{5}{|l|}{ Cost $(R \$ / k g)$} \\
\hline \multicolumn{5}{|l|}{ Receita } \\
\hline \multicolumn{5}{|l|}{ Income } \\
\hline Preço do leite (R\$/litro) & 0,52 & 0,52 & 0,52 & 0,52 \\
\hline Milk price (R\$/liter) & & & & \\
\hline Renda do leite (R\$/vaca/dia) & 11,97 & 12,33 & 11,91 & 12,52 \\
\hline Daily income (R\$/cow/day) & & & & \\
\hline Margem bruta (R\$/vaca/dia) & 6,02 & 6,79 & 6,73 & 7,49 \\
\hline Gross profitability (R\$/cow/day) & & & & \\
\hline
\end{tabular}

${ }^{1}$ Preços praticados na região de Viçosa/MG durante o mês de abril de 2003.

${ }^{1}$ Collect prices in Viçosa/MG (04/2003).

$\mathrm{R} \$ 1,47$ em relação à dieta sem casca. No cálculo para período de 30 dias, as dietas com 8,75; 17,5 e 26,25\% de casca permitiriam renda adicional de 23,1; 21,3 e 44,1 reais em relação à dieta sem casca de café.

Os gastos com as dietas neste experimento representaram em média 90,5 e 75,3\% da receita proveniente da venda do leite, para as dietas com 0 e 26,25\% de casca de café, respectivamente. O elevado preço dos alimentos concentrados (milho e farelo de soja) comumente utilizados na alimentação animal foram os principais responsáveis pelos altos custos das dietas. Neste sentido, a avaliação de alimentos alternativos, como os resíduos da agroindústria, na dieta de vacas lactantes pode contribuir para redução dos gastos com alimentação dos rebanhos e, ao mesmo tempo, garantir níveis satisfatórios de produtividade. 


\section{Conclusões}

O consumo de matéria seca, a produção e a composição do leite não foram alterados pela adição de casca de café nas dietas. Menor custo com alimentação e maior margem bruta foram obtidos com os níveis de casca de café utilizados. A inclusão deste resíduo em até $26,25 \%$ em substituição ao milho da ração concentrada de vacas em lactação, que representou $10,5 \%$ de casca de café na matéria seca da dieta, pode ser benéfica em condições de disponibilidade deste alimento.

\section{Literatura Citada}

BARCELOS, A.F.; ANDRADE, I.F.; Von TIESENHAUSEN, I.M.E.V. et al. Aproveitamento da casca de café na alimentaçãodevacas emlactação.In:REUNIÃOANUALDASOCIEDADE BRASILEIRA DE ZOOOTECNIA, 33., 1996, Fortaleza. Anais... Fortaleza: Sociedade Brasileira de Zootecnia, 1996. p.128-130.

BARCELOS, A.F.; ANDRADE, I.F.; Von TIESENHAUSEN, I.M.E.V. et al. Aproveitamento da casca de café na alimentação de novilhos confinados - resultados do primeiro ano. Revista Brasileira de Zootecnia, v.26, n.6, 1208-1214, 1997.

BRAHAM, J.E.; JARQUIN, R.; GONZÁLEZ, J.M. et al. Pulpa y pergamino de café. III. Utilización de la pulpa de café en forma de ensilaje. Archivos Latinoamericanos de Nutricion, v.23, 379-388, 1973.

CAIELLI. E.L. Uso da palha de café na alimentação de ruminantes. Informe Agropecuário, v.10, n.119, 36-38, 1984.

COCHRAN, R.C.; ADAMS, D.C.; WALLACE, J.D. et. al. Predicting digestibility diets with internal markers: Evaluation of four potential markers. Journal of Animal Science, v.63, 1476-483, 1986.

HAWKINS, G.E.; DAVIS, W.E. Changes in plasma free fatty acids and triglycerides in dairy cattle after dosing with coffee or caffeine. Journal of Dairy Science, v.53, n.1, p.52-54, 1970.

JUNG, H.G.; ALLEN, S. Characteristics of plant cell walls affecting intake and digestibility of forages by ruminants. Journal of Animal Science, v.73, n.9, 2774-2790, 1995.

LICITRA, G.; HERNANDEZ, T.M.; Van SOEST, P.J. Stantardization of procedures for nitrogen fractionation of ruminant feeds. Animal Feed Science and Technology, v.57, n.4, 347-358, 1996.

NASCIMENTO, C.G.H. Desempenho de animais suplementados a pasto na seca, utilizando casca de café. Lavras: Universidade Federal de Lavras, 2002. 43p. Dissertação (Mestrado em Zootecnia) - Universidade Federal de Lavras, 2002.
NATIONAL RESEARCH COUNCIL - NRC. Nutrient requirements of dairy cattle. 7.ed. Washington, D.C.: National Academy Press, 2001. 381p.

PEREIRA, M.N.; CORREA, C.E.S. Manejo dos sistemas de produção de leite em confinamento. In: SUSTENTABILIDADE DE SISTEMAS DE PRODUÇÃO DE LEITE A PASTO E EM CONFINAMENTO, 2001, Juiz de Fora. Anais... Juiz de Fora: Embrapa Gado de Leite, 2001. p.163.

RAMIREZ-MARTINEZ, J.R. Phenolic compounds in coffee pulp: quantitative determination by hplc. Journal Science Food and Agriculture, v.43, 135-144, 1988.

SANTOS, F.A.P. Manejo dos sistemas de produção de leite a pasto. In: SUSTENTABILIDADE DE SISTEMAS DE PRODUÇÃO DE LEITE A PASTO E EM CONFINAMENTO, 2001, Juiz de Fora. Anais... Juiz de Fora: Embrapa Gado de Leite, 2001. p.163.

SILVA, D.J.; QUEIROZ, A.C. Análise de alimentos: métodos químicos e biológicos. 3.ed. Viçosa, MG: Universidade Federal de Viçosa, 2002. 235p.

SNIFFEN, C.J.; O’CONNOR, J.D.; Van SOEST, P.S. et. al. A net carbohydrate and protein system for evaluating cattle diets. II. Carbohydrate and protein availability. Journal of Animal Science, v.70, n.11, 3562-3577, 1992.

SOUZA, A.L.; GARCIA, R.; PEREIRA, O.G. et al. Composição químico-bromatológica da casca de café tratada com amônia anidra e sulfeto de sódio. Revista Brasileira de Zootecnia, v.30, n.3, 983-991, 2001 (supl. 1).

UNIVERSIDADE FEDERAL DE VIÇOSA - UFV. SAEG Sistema de análises estatísticas e genéticas. Versão 7.1. Viçosa, MG. 1997. 150p. (Manual do usuário).

VALADARES FILHO, S.C.; ROCHA JR., V.R.; CAPPELLE, E.R. Tabelas brasileiras de composição de alimentos para bovinos. Viçosa, MG: Universidade Federal de Viçosa, 2001. 297p.

VALADARES, R.F.D.; BRODERICK, G.A.; VALADARES FILHO, S.C. et al. Effect of replacing alfalfa with high moisture corn on ruminal protein synthesis estimated from excretion of total purine derivatives. Journal of Dairy Science, v.82, n.12, 2686-2696, 1999.

VARGAS, E.; CABEZAS, M.T.; MURILO, B. et al. Efecto de altos niveles de pulpa de café deshidratada sobre el crecimiento y adaptación de novillos jóvenes. Archivos Latinoamericanos de Nutrición, v.32, n.4, 972-989, 1982.

Recebido em: 20/09/04 Aceito em: 15/07/05 